\title{
Spatial Dichotomy in Incidence and Impacts of Abandoned Structures on Residents in Ilorin, Nigeria
}

\author{
ADIGUN Folasade Oyenike ${ }^{*}$ ABOLADE Olajoke IGE James Olateju, \\ ADEOSUN Ayoyinka Odunayo OLADELE Joshua Abayomi \\ Department of Urban and Regional Planning, Ladoke Akintola University of Technology, \\ Ogbomoso, Oyo State, Nigeria \\ *Corresponding author
}

\begin{abstract}
The paper examined the spatial variation in the incidence, causes and impacts of abandoned structures in Ilorin, Nigeria. Primary data was collected through questionnaire from 581 residents in selected localities in urban and rural areas. Direct observation and physical counting were carried out to determine the incidence of abandoned structures in the study area. Data on incidence, prevalence and categories of abandoned structures in the study area were summarized using descriptive statistics such as frequencies and percentages. Chi-square was used to test the differences between incidence and causes of abandoned structures in urban and rural areas. Z-score was used to analyze the physical counting of the abandoned buildings and compared the relative raw scores from different localities in the study area on categories of abandonment. Analysis of Variance (ANOVA) was used to determine urban-rural variations in the incidence, causes and impacts of abandoned structures in the study area. Four indices were developed: Causes of Abandoned Structures Index' (CASI), Environmental Impact of Abandonment Index (EIAI), Psycho-Social Impact of Abandoned Structures Index (PSIASI) and Economic Impact of Abandonment Index (EcIAI). CASI, EIAI and PSIASI were employed respectively to measure causes, environmental and psycho - social impacts of abandonment in Ilorin. It is established that there is significant variation in the incidence and causes of abandoned structures between urban and rural areas of Ilorin. The most pronounced psychosocial effect of abandonment in the study area is 'theft' (PSIASI $=4.38$ ). Prominent economic variables of abandonment in the study area range from 'affecting communal development levy' (EcIAI $=3.88)$ to 'property value decline' $(\mathrm{EcIAI}=3.61)$ to property vandalization' (EcIAI $=3.60)$. The study concluded that environmental impacts of abandonment in the study area varied spatially. The study therefore suggests that abandoned structure should be identified and compiled by Town Planning Authorities after which the owners could be contacted and mandated to work on the structures based on the level of negative impacts associated with such structures. Some of the government owned abandoned properties could be auctioned or donated to the respective community for better usage.
\end{abstract}

Keywords: Abandonment, Development, Environmental Impacts, Residents

DOI: $10.7176 / \mathrm{JAAS} / 58-09$

Publication date:September $30^{\text {th }} 2019$

\subsection{Introduction}

Man is a product of his environment (Sampford, 2010). The environment of man either makes or mars him. The amalgam of influence of the environment on man, including: economic, social, physiological and psychological is very crucial to his existence and wellbeing (Sampford, 2010). The physical environment is considered the most pertinent component of the environment because it is that which the organism, individual, community or population is in direct contact with and whose effects are mostly evident and tangible (Folke, 2007). Major attributes of the physical environment as identified by Essagha (2003) include: the home, its structural stability, amenity, architecture and locational characteristics relative to the structures. In the context of planning and built environment, the physical environment is generally known as the built environment (Akindele, 2013). The built environment simply refers to the buildings and spaces between them (Osuide and Dimuna, 2005). Many developing countries particularly Nigeria is experiencing unprecedented city expansion coupled with high rate of negligence in city management thus resulting in fast decay of her built-up environment (Ahianba et al 2008). The factors responsible for this can be attributed to rapid and uncontrolled urbanization, rural-urban migration and decades of steady economic downturn, negligent urban housekeeping and decay of urban structure (World Bank, 2008).

Urban structures within the built up environment are inevitably deteriorating and may subsequently be abandoned as they age unless they are properly maintained (Olaniyi, 2005; Akindele, 2013). Also, changes in technological and commerce trend may edge out some structures; making them obsolete and prone to abandonment (Akindele, 2013). The phenomenon is also evident in Ilorin; the study area is not different. Obsolete structures and infrastructures are part of the core city landscape. Spurred by the family traditional and communal land tenure system, the old buildings remain where they are as a rule either boarded or not; and no one could put them into use without general consensus of the family (Adedibu and Akindele, 2007; Akindele, 2013). 
While some of these structures are actually under construction but are characterized by bushy growth in (if not roofed) and around them, some are old and dilapidated and partly roofed (Akindele, 2007; Akindele, 2013). It is even not uncommon to see some buildings dilapidating yet under construction. The age of some of these structures are only better imagined. Some of the structures carry red paint marks ensigned by the officers of the local planning authority, which connote that they are defaulters to the rules of development control in the city (Akindele, 2013). They are therefore wrong structures in wrong places performing wrong functions because of wrong environmental management attitudes (Akindele, 2011).

More than 800 million people (about $12 \%$ of the world's population) were estimated to be living in slums as at 2009 and the number may increase to two billion by 2020 (UN-Habitat, 2009). The resulting situation is the several attempts to build dwelling units by individual urban poor. The quest for home ownership especially in Nigeria found expression in the facts that: a house is not just a shelter; it is a status symbol, an economic investment, the most valued asset, with profound impact on human health, welfare and productivity as well as the social, cultural, economic and historical or heritage value in any society (Olatubara, 2007). With the low income of urban poor, a long term saving and lots of determination to have structures of their own had encouraged many to start a project of building. Many have been able to secure land at a relatively preferred area, and many have started on erecting a building. But with living cost and economic drift in the country and allied reasons, a lot of residential structures have been abandoned (Akindele, 2013).

Abandonment is not hard to notice. It is rather noticeable and worst still entrenched within our rural and urban environments. Yet, it is not included in the definition of urban blight or community decay (Setterfield, 1997). Meanwhile, abandonment principally blights the environment. (Setterfield, 1997). Dilapidated structures are not supposed to be abandoned or they will throw the structures contiguous into a cycle of vicious and the issue of urban blight becomes more difficult to handle.

The implication of abandonment of structures can be enormous. It is capable of inducing or at least encourages one or more environmental, social and economic problems within the developed area. For instance, the presence of abandoned structures has been observed to encourage arson and other crimes, waste dump, and property value decline where they exist (Adedibu and Akindele, 2007). Abandoned structures unnecessarily mark the area in which they are found with slum characteristics. The abandoned sites are replete with unhealthy pollution activities especially within the area where toilet and waste disposal facilities are inadequate or nonexistent (Olaniyi, 2005). This may account for why the prevalent health problems in most cities are diarrhea, typhoid fever and other filth-related health problems (Spelman, 1993). Such abandoned sites are also vagrants' delight, miscreants' convenient abode and the den where criminals plan, conclude or perpetrate nefarious acts in the neighbourhood (Spelman, 1993). Agbola (2002) pointed out that major dangerous spots in most Nigerian cities are mostly those areas where development is not complete, where there are shanty developments and unused structures which serve as the settlement of miscreants. The fore goings confirms two things: first that the incidence of abandoned structures occurs in almost every growing cities of the world and second that abandoned structures are associated with crime. Thus, this study assessed spatial variation in incidence, causes and impacts of abandoned structures on residents with a view to proffering planning recommendations that are visible and practicable.

\subsection{The Study Area}

Ilorin is located in the transitional zone between the savannah zones and as a gateway linking the Northern Nigeria with the Southern part of Nigeria. It is the administrative seat of Kwara State Government. It is located between longitude $4^{0} 25^{\mathrm{I}} \mathrm{E}$ and $5^{0} 15^{\mathrm{I}} \mathrm{E}$ and between latitude $8^{0} 10^{\mathrm{I}} \mathrm{N}$ and $8^{0} 45^{\mathrm{I}} \mathrm{N}$. Ilorin consists of three local government areas, which are Ilorin East, Ilorin West and Ilorin South local governments with their headquarters at Oke-Oyi, Oja - Oba and Fufu respectively. Its population is 777,667 (NPC, 2006). Over the years, the city has grown spatially and there has been influxes of people which were necessitated by spontaneous development as well as corresponding increase in commercial and industrial activities. A tour around Ilorin shows that more buildings have been abandoned in the rural areas than in the urban centres. This may be due to the fact that majority of the populace of the rural areas go in search of green pasture in the urban centre. This abandonment have diverse effects on residents' in Ilorin. 


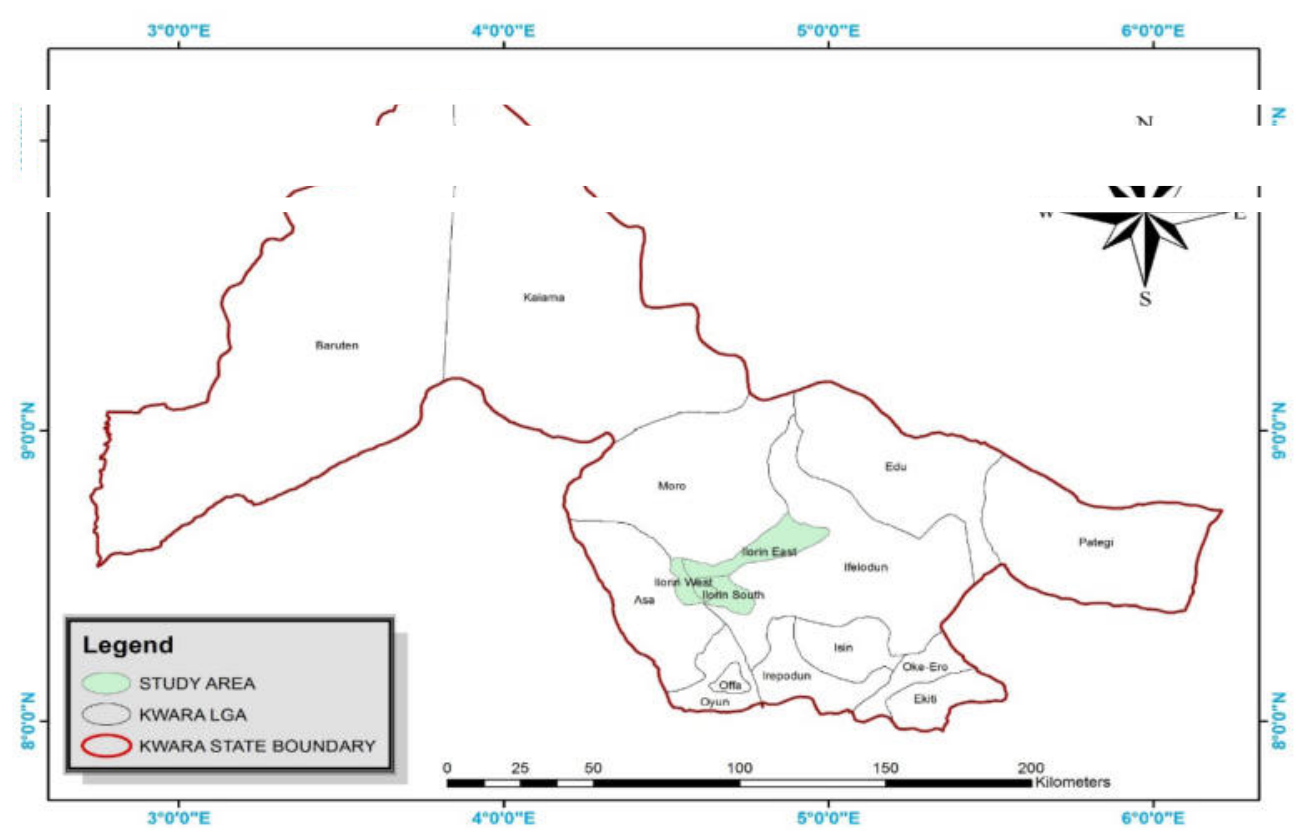

Figure 1: Study Area within the Context of Kwara State

Source: Kwara State Ministry of Housing and Urban Development, 2012

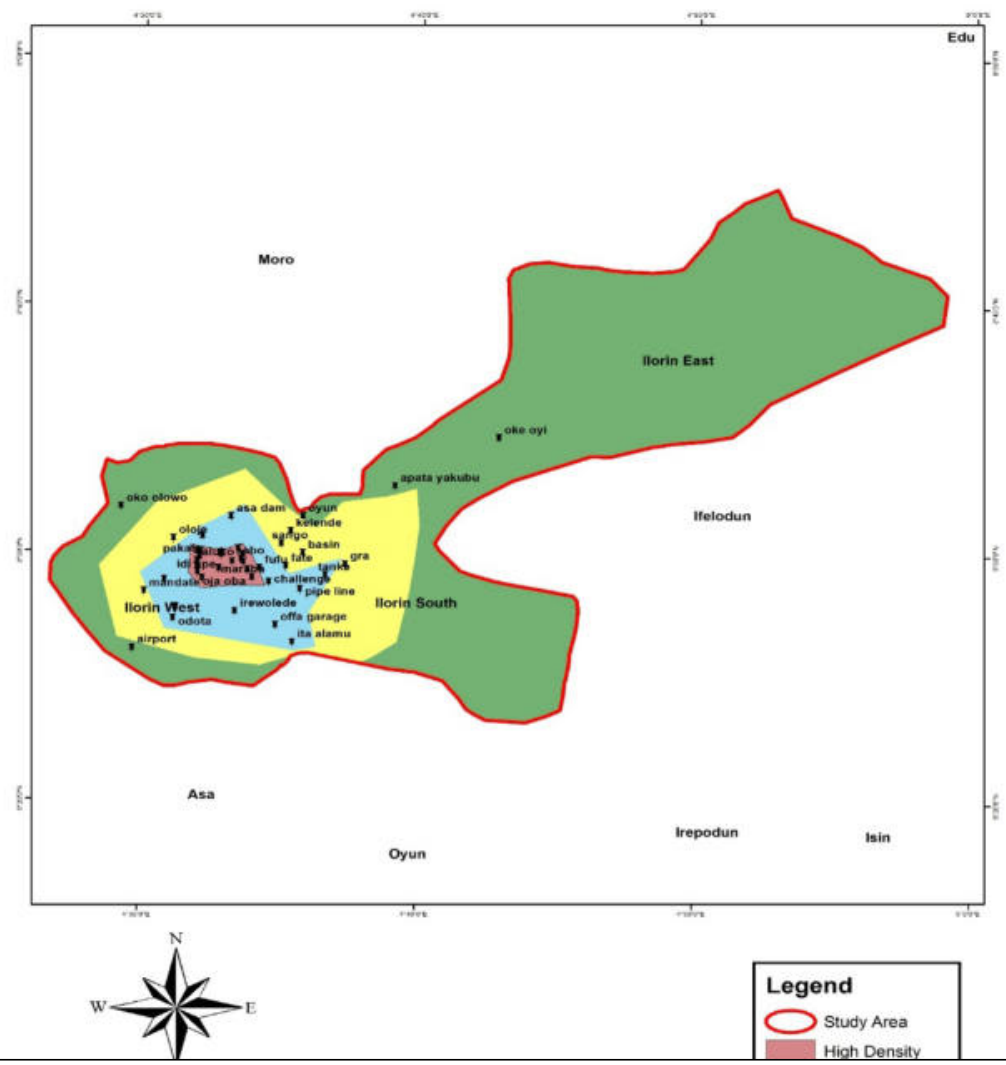

\section{Figure 1.1: Kwara State within the National Context}

Figure 2: Study Area Delineation

Source: Authors Field Survey and Google Earth, 2015 


\section{CHAPTER TWO}

\subsection{MATERIALS AND METHODS}

The study utilizes primary data obtained directly from the field through reconnaissance survey, direct observations and physical counting of abandoned buildings and copies of structured questionnaire were administered on residents in the study area. In addition to this, secondary information such as imagery of Ilorin was obtained via Google Earth. Maps were also obtained from Physical Planning Authority in Ilorin. These were used to complement the primary data. The frontier of information on the subject matter was obtained from published and unpublished articles and projects. Ilorin comprises of three local government areas which are Ilorin East, Ilorin West and Ilorin South respectively. The multi-stage sampling techniques were adopted. Stratified sampling technique was first used to segregate Ilorin into two strata, which are rural and urban areas. Rural areas are predominantly low density as justified by Ogbazi (1995) but are inhabited by low income populace. All localities were segregated under each stratum. For instance, localities that showed the traits of rural settings are identified and classified under rural areas. Further clarification of Ilorin was also extracted from Thomas Brinkhoff (2013) in classification of Ilorin localities into urban and rural areas. These constituted the sample frame. Population of buildings in each locality/village was documented via Google Earth and field survey. Total building population observed in the sampled localities in urban area of Ilorin was 4265. Also, total building population observed in sampled localities/villages in the rural area was 1270 . From this $0.1 \%$ of the building population was taken as the sample size. Four hundred and twenty eight questionnaires were distributed in urban area while one hundred and twenty seven questionnaires were distributed in rural area of Ilorin making a total number of 581 questionnaires administered for this study.

Questionnaire administration was limited to selected households in sampled localities with the household heads as respondents. In cases where the household heads were not available, other available adult members were sampled. The household which serves as the unit of questionnaire administration and collection of data was selected in each 22 selected streets or footpaths using random systematic sampling techniques; where the first house was chosen at random and subsequent ones were chosen at an interval of 10 . Physical counting of observed abandoned buildings was done to know the incidence of abandoned structures in the study area. This was done to compliment the responses of the respondents in the study area.

Data on incidence and prevalence of abandoned structures, and categories of abandoned structures in the study area were summarized into frequencies and percentages. Chi-square was used to test the variation in the incidence and causes of abandoned structures between urban and rural areas. Z-score was used to analyze the physical counting of the abandoned buildings and compared the relative raw scores from different localities in the study area on categories of abandonment. Inferential statistics such as Analysis of Variance (ANOVA) and Linear Regression Model were employed. ANOVA was used to determine urban-rural variations in the incidence, causes and impacts of abandoned structures in the study area. The method of data analysis is justified because it helps to determine whether there is significant variation between dependent variable which is the incidence of abandoned structures and the independent variables which are the two areas (rural and urban). Four indices were developed: Causes of Abandoned Structures Index' (CASI), Environmental Impact of Abandonment Index (EIAI), Psycho-Social Impact of Abandoned Structures Index (PSIASI) and Economic Impact of Abandonment Index (EcIAI). CASI, EIAI and PSIASI were employed respectively to measure causes, environmental and psycho - social impacts of abandonment in Ilorin. Linear Regression was used to test relationship between the incidence of abandonment and livability of resident. The incidence of abandoned structures constituted the independent variable while livability of residents' was dependent variable.

\subsection{Incidence of Abandoned Structures}

Table 1: Results of ANOVA on Urban-Rural Variation in the Incidence of Abandoned Structures in the Study Area using the Counted Data

\begin{tabular}{llllll} 
Source of Variation & Sum of square & df & Mean square & F & Sig. \\
Between Groups & 4668.933 & 1 & 2334.467 & 6.819 & 0.000 \\
Within Groups & 34198.000 & 374 & 2334.833 & & \\
Total & 38866.933 & 375 & & & \\
\hline
\end{tabular}

Source: Author's Field Survey, 2015

The result of ANOVA established the variation in the incidence of abandoned structures between the two areas of Ilorin (Table 1). It is observed that the incidence of abandoned structures varies significantly between urban and rural areas of Ilorin. That is there is significant variation in the number and categories of abandoned structures between the urban and rural areas of Ilorin. This is expected because the area covered in urban area is more than the rural $(\mathrm{F}=6.484$ and $\mathrm{p}=0.011$ at $95 \%$ confidence level). It can however be inferred that presence of abandoned structures is not the same in the two areas of Ilorin. 


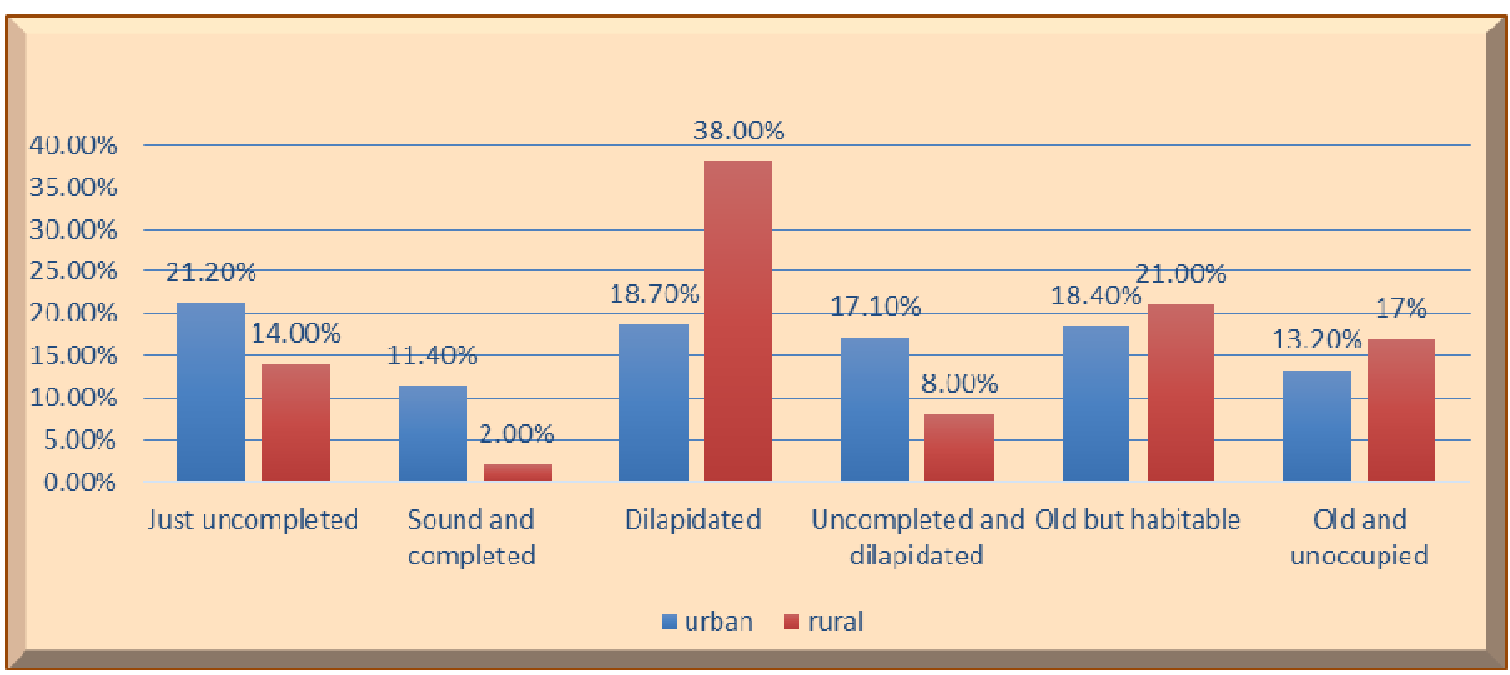

Figure 3: Urban-Rural Variation in the Prevalence of Abandoned Structures.

Source: Authors Computation (2015)

The magnitude of the six categories of abandoned structures varies in the study area as documented in Figure. 3. In urban areas of Ilorin, the most noticeable categories of abandonment is 'uncompleted abandoned structures' $(21.2 \%)$. Next to this is abandonment due to 'dilapidation' $(18.7 \%)$, then 'old but habitable abandoned structures' (18.4\%). Others are: 'abandoned structures due to incompletion and dilapidation' (17.1\%), 'sound and completed structure abandonment' were only $11.40 \%$. It can therefore be deduced that there are different categories of structure abandonment observed in the study area. In the rural area of Ilorin, 'dilapidated abandoned structures' (38\%) is more pronounced, followed by the 'old but habitable abandoned structures' $(21 \%)$ as detailed in Figure 3. Next to this is old but unoccupied abandoned structures' (17\%). Comparatively between the urban and rural area, the incidence of all categories of abandoned structures differs.

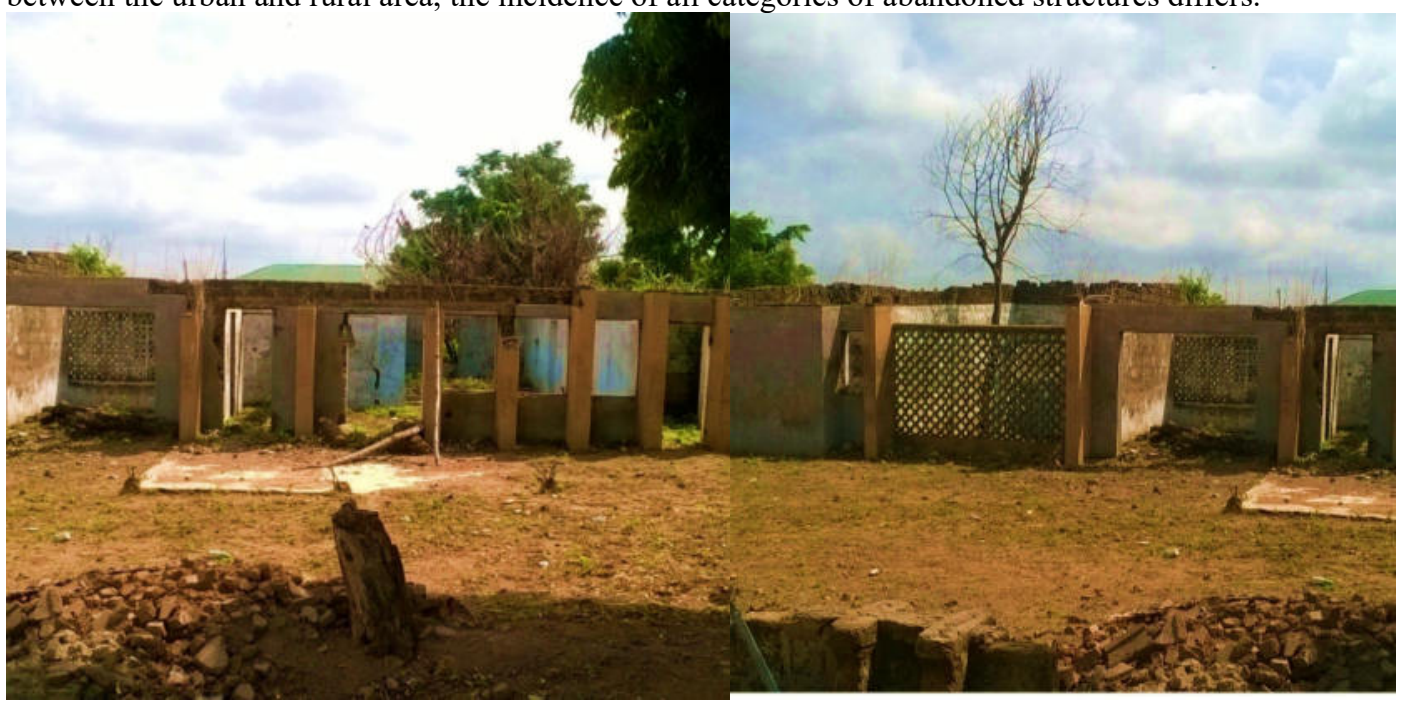

Plate 1: Uncompleted and Dilapidated Abandoned Structures in the Odota.

Source: Author's Field Survey, 2015 


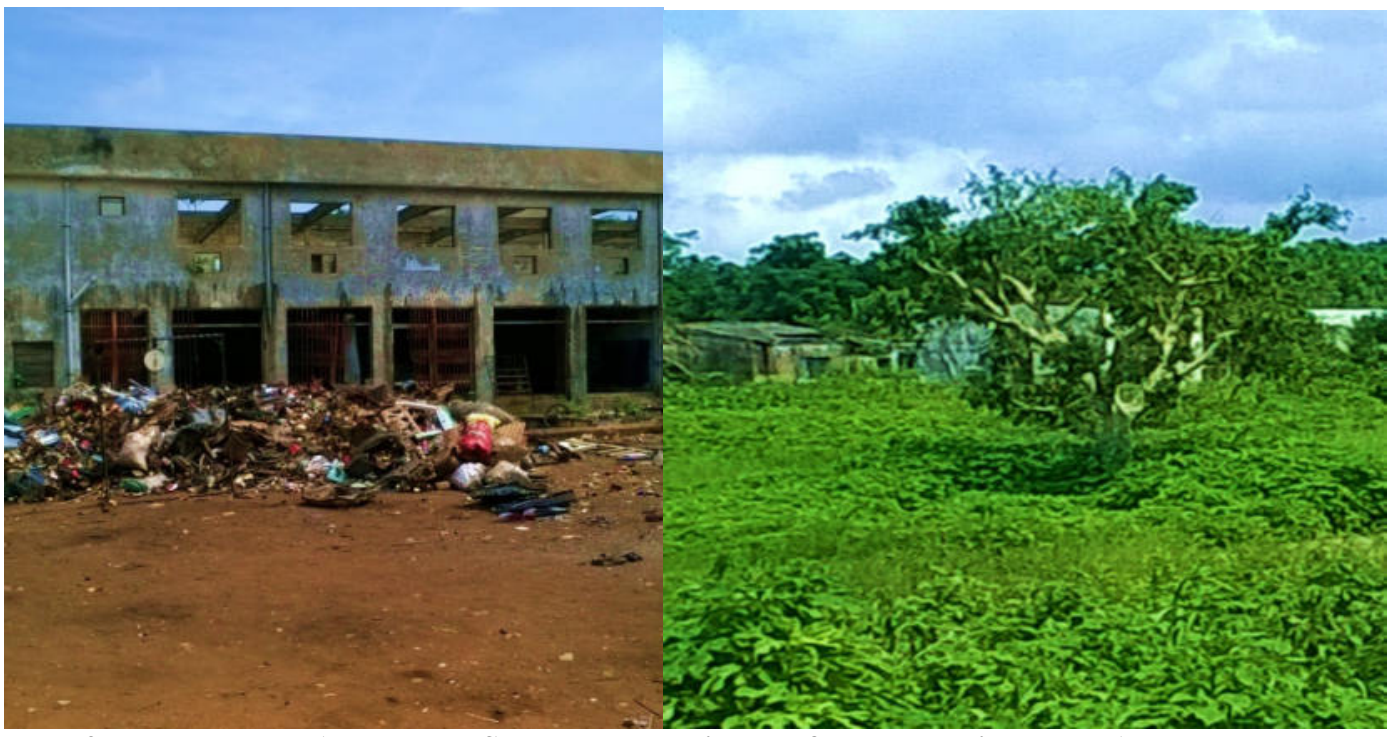

Plate 2: Uncompleted Abandoned Structure Turn into Refuse Dumps in Tanke Area.

Source: Author's Field Survey, 2015

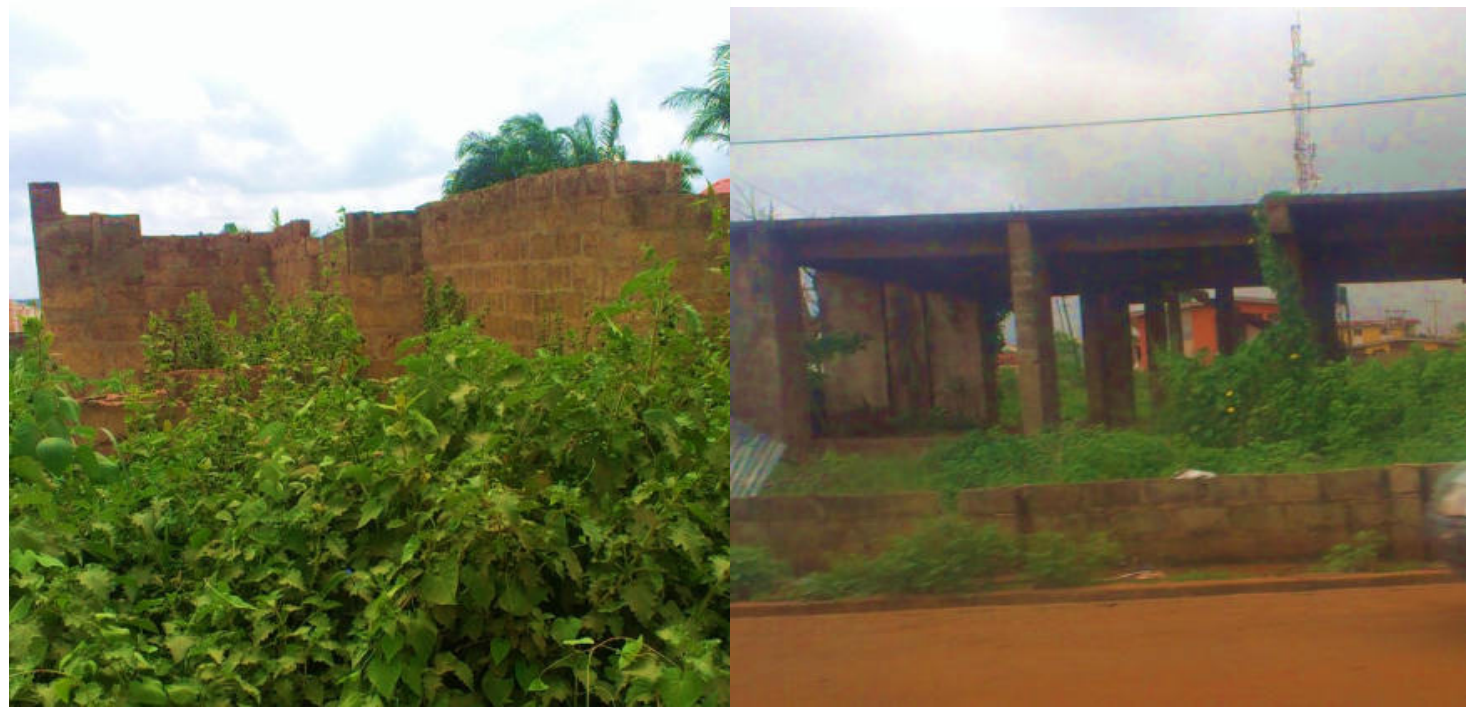

Plate 3: Uncompleted and Bushy Abandoned Structures in Maraba Area.

Source: Author's Field Survey, 2015 


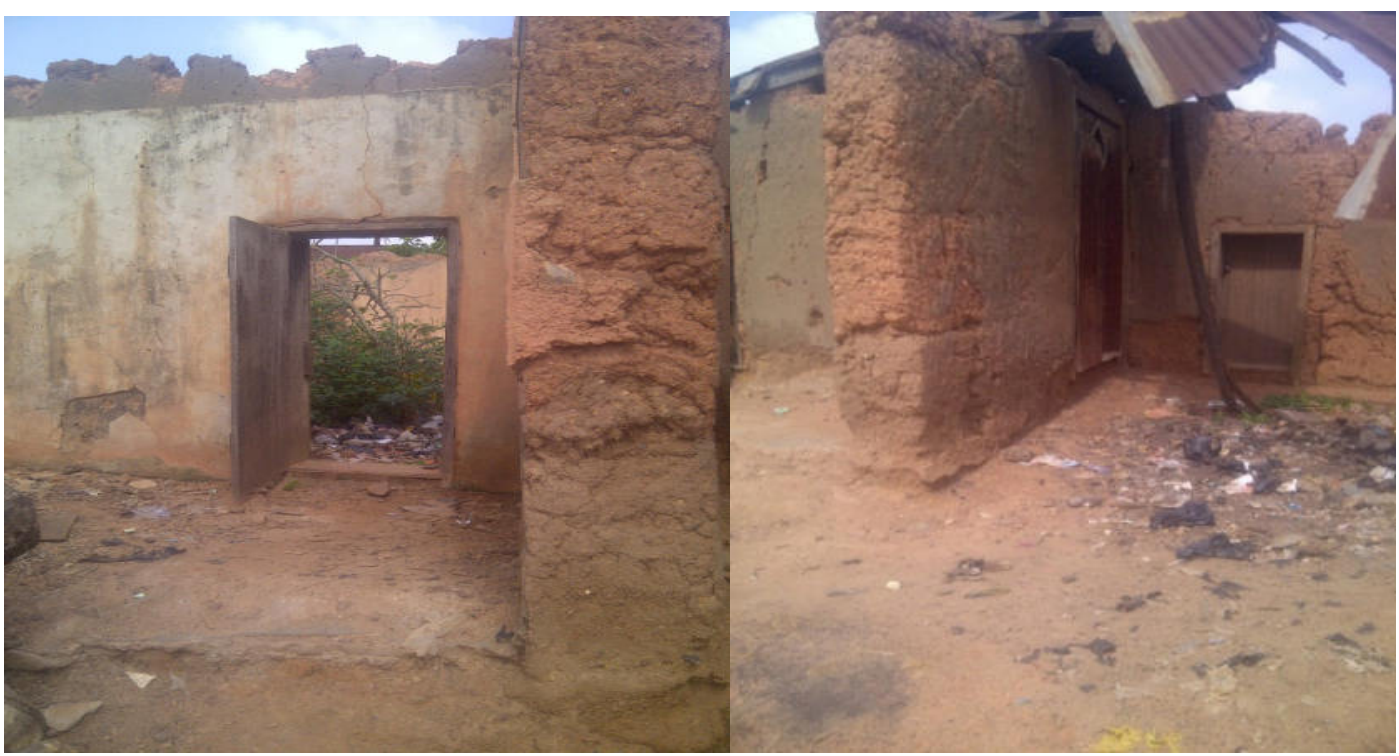

Plate 4: Dilapidated and Deteriorated Abandoned Structures in Oke-oyi Area.

Source: Author's Field Survey, 2015

\subsection{Causes of Abandoned Structures}

CASI was developed to measure the causes of abandoned structures. In order to arrive at CASI, eleven variables associated with the causes of abandonment were rated by respondents. These include death of developer/owners, lack of fund, dilapidation, disaster, migration, robbery, spiritualism, extended family crisis, litigation, government policy, discomfort among several others. The extent of the various causes associated with incidence of abandonment was measured between the two areas of Ilorin (urban and rural). The mean CASI for the whole study area was computed for the two areas (i.e. urban and rural area) and compared with CASI of each variable.

The eleven causes were differentiated into two groups. First are variables with positive deviation above the mean CASI value while the second group includes those with negative deviation below the mean CASI value. This implies that variables with positive deviation contribute greatly to high incidence of abandoned structures while variables with negative deviation are not predominant causes of abandoned structures in the study area.

The mean CASI value for the whole study areas is 3.90 (Table 2). This is higher than the mean CASI for urban (3.46) but less than that of rural (4.34) area. In urban area, most pronounced causes of abandoned structures with high CASI values are 'death of developer/owners' $(\mathrm{CASI}=4.54)$, 'lack of fund' (CASI $=4.51$ ), 'migration' (CASI = 3.38) and 'dilapidation' (CASI = 3.65) while causes of abandoned structure with low CASI values are 'litigation' (CASI $=2.81)$ and 'extended family crisis' $($ CASI $=2.99)$ ". In the rural area, most pronounced causes of abandoned structures with high CASI values are 'migration' (CASI $=4.82)$, 'death of building owners' $(\mathrm{CASI}=4.65)$, 'lack of fund' $(\mathrm{CASI}=4.57)$, and 'dilapidation' $(\mathrm{CASI}=3.95)$ " each while causes of abandonment variables with low CASI values are 'litigation' and 'government policy' each with CASI value of 2.99. On the aggregate, the most pronounced causes of abandonment in the study area with positive values are 'death of building owners' $(\mathrm{CASI}=0.70)$, 'lack of fund' $(\mathrm{CASI}=0.64)$, 'migration' $(\mathrm{CASI}=0.11)$.

Among the factors attributed to high incidence of abandonment is sudden death of developer/owner which probably resulted from various predictable and unpredictable factors. Lack of fund as a factor of abandonment could be easily interpreted from current global economic recession and economic crisis in various States of the Federation featuring nonpayment of salary, high inflation etc. These may retard or even hindered developer from completing an ongoing development. Also migration is explainable with the fact people goes in search of greener pasture such as better employment appointment in the study area. The observed urban-rural variation in the causes of abandoned structures in the study area is statistically significant with $\left(X^{2}=9.641, \mathrm{df}=1, \mathrm{p}=0.000\right)$. 
Table 2: Causes of Abandoned Structures in the Study Area.

\begin{tabular}{|c|c|c|c|c|c|}
\hline \multirow[t]{2}{*}{ Causes } & \multicolumn{2}{|c|}{ CASI for Areas } & \multirow[t]{2}{*}{ CASI } & \multirow{2}{*}{$\begin{array}{l}\text { CASI- } \\
* \text { CASI }\end{array}$} & \multirow{2}{*}{$\begin{array}{l}\text { (CASI } \\
{ }^{*} \text { CASI) }\end{array}$} \\
\hline & Urban & Rural & & & \\
\hline Death of owner & 4.54 & 4.65 & 4.60 & 0.70 & 0.4900 \\
\hline Lack of fund & 4.51 & 4.57 & 4.54 & 0.64 & 0.4096 \\
\hline Migration & 3.38 & 4.82 & 4.01 & 0.11 & 0.0121 \\
\hline Dilapidation & 3.65 & 3.95 & 3.80 & -0.10 & 0.0100 \\
\hline Discomfort & 3.15 & 3.37 & 3.66 & -0.24 & 0.0576 \\
\hline Disaster & 3.44 & 3.41 & 3.43 & -0.47 & 0.2209 \\
\hline Robbery & 3.31 & 3.30 & 3.31 & -0.59 & 0.3481 \\
\hline Spiritualism & 3.20 & 3.13 & 3.17 & -0.73 & 0.5329 \\
\hline Government policy & 3.01 & 3.07 & 3.04 & -0.86 & 0.7396 \\
\hline Extended family crisis & 2.99 & 2.99 & 2.99 & -0.91 & 0.8281 \\
\hline Litigation & 2.81 & 2.99 & 2.90 & -1.0 & 1.0000 \\
\hline Total & 37.99 & 45.25 & 42.9 & & \\
\hline *CASI & 3.45 & 4.34 & 3.90 & & \\
\hline
\end{tabular}

Source: Author's Computation (2015)

ANOVA test was used to establish the significance of the spatial variation in the causes of abandonment between the two areas of Ilorin. It was observed that some causes of abandoned structures vary significantly between two areas while some causes of abandoned structures reported no significant between areas in the study area. For instance causes such as death of developer, dilapidation, lack of fund, disaster, and migration observed to a value of $\mathrm{F}=1.611,0.388,0.356,0.145$ and 314.002 with a value of $\mathrm{p}=0.182,0.534,0.551,0.203$ and 0.861 . The probability value suggests that there is no significant variation in the causes of abandonment between the two areas of Ilorin at $95 \%$ confidence level. It can therefore be inferred that the causes of abandoned structures between urban and rural do remain the same in the study area.

\subsection{Environmental Impact of Abandonment in the Study Area.}

Presented on Table 3 is the EIAI of the two areas of Ilorin for an insight into respondents' perceived impacts of abandonment experienced in the study area. Urban area has the highest EIAI mean value $($ EIAI $=3.60)$ compared to the rural area $(E I A I=3.52)$. The EIAI mean value for the study area is 3.56. The EIAI mean value of urban area is above the mean EIAI for the study area while EIAI mean value for rural area is below it. This implies that the urban dwellers experienced more environmental impact of abandonment incidences than the residents of the rural area. It could then be concluded that rural dwellers experience less impact of abandonment incidence than urban dwellers.

On the aggregate level, environmental impact of abandonment highly experienced by residents include 'smoker site' (EIAI = 3.99), 'disfigure neighbourhood landscape' (EIAI = 3.91), 'defecation venue, refuse dumpsites' (EIAI $=3.70 \mathrm{each}$ ), and 'fueling of bush burning' (EIAI = 3.56). The environmental impact that residents perceived less include 'pollution' (EIAI $=3.40)$, 'lunatic residence and criminals hideout' $($ EIAI = 3.41) each, and 'temporal store of stolen goods' (EIAI = 3.42). It can therefore be inferred that the more the incidence of abandoned structures, the more its environmental effects perceived by residents in the study area.

In the urban area of Ilorin, environmental impacts of abandonment variables that residents observed more include 'smoking site' (EIAI = 3.97), 'disfigure neighbourhood landscape' (EIAI = 3.92), 'defecation venue and refuse dump site' (EIAI = 3.70) each, 'fueling of bush burning' (EIAI = 3.73). Environmental impacts of abandonment variables experienced less by residents include 'lunatic residence' (EIAI $=3.40$ ), 'pollution' (EIAI $=3.42$ ) and 'temporal store of stolen goods' (EIAI $=3.44)$.It can therefore be inferred that the more the incidence of abandoned structures, the more its environmental effects perceived by residents in the urban area.

Furthermore, in the rural area of Ilorin, environmental impacts of abandonment that residents observed more include 'smoking site' (EIAI $=4.01)$, 'disfigure neighbourhood landscape' (EIAI $=3.90)$, 'defecation venue and refuse dump site' each with EIAI value of 3.69 and 'vagrant settlement' (EIAI = 3.54). The environmental impacts of abandonment that residents experienced less in rural area include 'arson' (EIAI = 3.28), 'criminals' hide-out and pollution' each with EIAI value of 3.37, 'fueling of bush burning and temporal store of stolen goods' each with EIAI value of 3.39. 
Table 3: Environmental Impact of Abandoned Structures in the Study Area.

\begin{tabular}{|c|c|c|c|c|c|}
\hline \multirow[t]{2}{*}{ Variables } & \multicolumn{2}{|c|}{ EIAI for Areas } & \multirow[t]{2}{*}{ EIAI } & \multirow{2}{*}{$\begin{array}{l}\text { EIAI } \\
* \text { EIAI }\end{array}$} & \multirow[t]{2}{*}{ - $\quad(\text { EIAI - *EIAI })^{2}$} \\
\hline & Urban & Rural & & & \\
\hline Smokers site & 3.97 & 4.01 & 3.99 & 0.43 & 0.1849 \\
\hline Disfigure neighbourhood landscape & 3.92 & 3.90 & 3.91 & 0.35 & 0.1225 \\
\hline Defecation venue & 3.70 & 3.69 & 3.70 & 0.14 & 0.0196 \\
\hline Refuse dump site & 3.70 & 3.69 & 3.70 & 0.14 & 0.0196 \\
\hline Fueling of bush burning & 3.73 & 3.39 & 3.56 & 0.00 & 0.000 \\
\hline Vagrant Settlement & 3.55 & 3.54 & 3.55 & -0.01 & 0.0001 \\
\hline Reptiles lodge & 3.49 & 3.43 & 3.46 & -0.10 & 0.0100 \\
\hline Odour/smell from waste & 3.50 & 3.42 & 3.46 & -.0 .10 & 0.0100 \\
\hline Arson & 3.61 & 3.28 & 3.45 & -0.11 & 0.0121 \\
\hline Criminal meeting center & 3.45 & 3.43 & 3.44 & -0.12 & 0.0144 \\
\hline Temporal store for stolen goods & 3.44 & 3.39 & 3.42 & -0.14 & 0.0196 \\
\hline Criminals hideout & 3.45 & 3.37 & 3.41 & -0.15 & 0.0225 \\
\hline Lunatic Residence & 3.40 & 3.41 & 3.41 & -0.15 & 0.0225 \\
\hline Pollution & 3.42 & 3.37 & 3.40 & -0.16 & 0.0256 \\
\hline TOTAL & 50.33 & 49.32 & 49.83 & & \\
\hline *EIAI & 3.60 & 3.52 & 3.56 & & \\
\hline
\end{tabular}

Source: Author's Field Survey, 2015

Considering the EIAI mean value of the two areas, it can be deduced that urban dwellers perceived more environmental effects than rural dwellers. This is evident that more incidence of abandoned structures were physically counted in urban than rural area, also residents in urban area dump refuse in uncompleted and dilapidated abandoned buildings which pollute the environment due to lack of provision for refuse collection center. Conversely, bushy and uncompleted abandoned building can be vulnerable to burning in the process of burning the bush /waste. Stolen goods are temporarily kept in nearby abandoned buildings in urban area. On the other hand, the (garage) tout in urban area uses abandoned structures for smoking their marijuana which have effect on neighbouring residents.

Environmental variables in rural area greater index value than urban area include smokers' site and lunatic residence. This implies that dilapidated abandoned structures that is pronounced in rural area attracts smoker in smoking their marijuana as similarly observed in urban settings. Lunatic one resides in abandoned structures in rural than in urban probably because of their individualism that is rural dweller shows a little bit concern or mercy to the victims. Also, the victims gain access to fruit which serve as food for them in rural area due to the fact that they are predominantly farmers which makes the victims stayed a bit longer before change in location.

\subsection{Urban-Rural Variation on Environmental Impacts of Abandonment Observed/Experienced in the} Study Area.

This section attempts to establish the urban-rural variation in the environmental impacts of abandoned structures in the study area. However, the study therefore uses ANOVA tools to establish the result if there is urban-rural variation in the impacts perceived by respondents in the study area. Some of the environmental impacts include pollution, vagrant settlement, refuse dump, criminals' hideout among several others. The results is presented in Table below

Table 4: Urban -Rural Variation in Environmental Impacts of Abandoned Structures in the Study area.

\begin{tabular}{|l|r|r|r|r|r|}
\hline & \multicolumn{1}{|c|}{ Sum of Squares } & \multicolumn{1}{c|}{ df } & \multicolumn{1}{c|}{ Mean Square } & F & Sig. \\
\hline Between Groups & .036 & 1 & .036 & .893 & .353 \\
Within Groups & 1.061 & 26 & .041 & & \\
Total & 1.097 & 27 & & & \\
\hline
\end{tabular}

Source: Author's Field Survey, 2015

Table 4 showed the result of ANOVA establishing the spatial variation in the environmental effects of abandonment between the two areas of Ilorin. According to the table, it is observed that most of the effects of abandoned structures do not vary significantly between areas with $\mathrm{F}=0.893$ and $\mathrm{P}=0.353$. The probability value suggests that there is no significant variation in the environmental effect of abandonment between the two areas of Ilorin at $95 \%$ confidence level. It can therefore be inferred that the environmental effect of abandoned structures between urban and rural do remain the same in the study area. 


\subsection{Psycho-Social Impact of Abandonment in the Study Area}

This section provides an insight in the psycho-social impact of abandonment experienced or observed by residents in their environment. Presented in Table 5 are the values of "Psycho-Social Impact of Abandoned Structures" (PSIASI) for the whole study area which comprises of urban and rural areas. The mean PSIASI value for the study area is 3.70; a value less than the PSIASI value of urban area (3.78) but high than the PSIASI value of rural area with PSIASI $=3.63$. Considering the mean PSIASI of the two areas, psycho-social effects of abandonment are higher in urban than rural area. It could then be concluded that rural dwellers experience less psycho-social effects of abandoned structures compared to urban dwellers.

Considering the study area as a whole, residents observed higher level of psycho-social effect of abandonment about certain variables. These are greater risk of 'theft' (PSIASI = 4.39); 'poor aesthetic look' (PSIASI $=4.11)$; 'fear of robbery' (PSIASI = 3.84) and rape' (PSIASI = 3.82); respectively. Certain psychosocial effects variables that residents perceived less include 'drug abuse' (PSIASI = 3.16); 'ghost zone' (PSIASI = 3.36); 'afraid of building collapse' (PSIASI = 3.53); 'stress' (PSIASI = 3.55); 'avoid walking at night' (PSIASI $=3.60$ ); and 'staying in door' (PSIASI = 3.67). It can therefore be deduced that the most and least PSIASI impacts perceived by residents in study area include 'theft' and 'drug abuse'. The implication of this can be associated with global economic meltdown coupled with act of theft among some (unemployed) youths of nowadays.

Within the urban centre, residents perceived some psycho-social effects of abandonment highly than others. These are greater risks of 'theft' (PSIASI $=4.43$ ); 'poor aesthetic look' (PSIASI $=4.22$ );'fear of robbery' $($ PSIASI $=4.08)$; and 'rape' (PSIASI $=3.83$ ). Category of variables for which residents observed less psychosocial effect in urban center include 'drug abuse' (PSIASI = 3.29); 'ghost zone' (PSIASI = 3.37); 'fear of building collapse' (PSIASI = 3.53); 'avoid walking at night' and 'stress' (PSIASI $=3.63$ ) each. The implication of this is that urban dwellers are financially buoyant than rural dwellers making them vulnerable to act of theft as well as fear of robbery. It can therefore be deduced that the most and least psycho-social effects perceived by residents in the urban center include 'theft' and 'drug abuse'.

Considering the mean PSIASI of the two areas, urban area perceived more psycho-social effects than rural dweller. This is due to the fact that more affluent people live in urban area than rural area thereby act of theft is more pronounced in urban making them vulnerable to fear of robbery than rural area. Urban dwellers are at greater risk of rape than rural area probably because they got exposed to sex at tender age and this act usually happens in abandoned structures in their school or neighbourhood. Aesthetic look of the environment were observed due to presence of abandoned structures in urban area probably because of their level education and exposure than rural area.

Table 5: Psycho-Social Impact of Abandoned Structures (PSIASI) in the Study Area.

\begin{tabular}{|llllll|}
\hline Variables & PSIASI for Area & PSIASI & PSIASI * & (PSIASI $^{*}$ \\
& Urban & Rural & & *PSIASI & *SIASI) \\
\hline Theft & 4.43 & 4.35 & 4.39 & 0.69 & 0.4761 \\
\hline Poor Aesthetic Look & 4.22 & 3.99 & 4.11 & 0.41 & 0.1681 \\
\hline Fear of Robbery & 4.08 & 3.59 & 3.84 & 0.14 & 0.0196 \\
\hline Rape & 3.83 & 3.80 & 3.82 & 0.12 & 0.0144 \\
\hline Staying In Door & 3.72 & 3.60 & 3.67 & -0.03 & 0.0009 \\
\hline Avoid Walking at Night & 3.63 & 3.56 & 3.60 & -0.10 & 0.0100 \\
\hline Stress & 3.63 & 3.47 & 3.55 & -0.15 & 0.0225 \\
\hline Fear Of Building Collapse & 3.53 & 3.53 & 3.53 & -0.17 & 0.0289 \\
\hline Ghost Zone & 3.37 & 3.35 & 3.36 & -0.34 & 0.1156 \\
\hline Drug Abuse & 3.27 & 3.02 & 3.16 & -0.54 & 0.2916 \\
\hline TOTAL & 37.73 & 36.26 & 36.99 & & \\
\hline *PSIASI & 3.78 & 3.63 & 3.70 & & \\
\hline Source: Authors & & &
\end{tabular}

Source: Author's Field Survey, 2015

Within the rural area, residents observed higher level of psycho-social effect of abandonment about certain variables. These are greater risk of 'theft' (PSIASI = 4.35); 'poor aesthetic look' (PSIASI = 3.99); 'rape' $($ PSIASI $=3.80)$ and 'staying indoor' (PSIASI $=3.60)$. Category of variables for which residents observed less psycho-social effect in rural area include 'drug abuse' (PSIASI = 3.02); 'ghost zone' (PSIASI = 3.35); 'stress' (PSIASI = 3.47); ' afraid of building collapse' (PSIASI = 3.53) among several others. It can therefore be inferred that the most and least psycho-social effects perceived by residents in the rural area include 'theft' and 'drug abuse' which is the same as in urban area. This implies that both urban and rural dwellers are affected by the incidence of abandoned structures in all facets. Conversely, considering the two areas, rural dwellers perceived 
less psycho-social effects of abandonment compared to urban residents.

Table 6: Urban-Rural Variation in Psycho-Social Impacts of Abandoned Structures in the Study Area

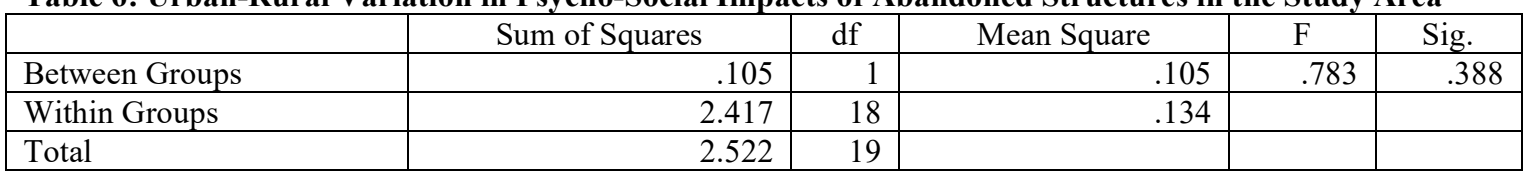

Source: Author's Field Survey, 2015

Table 6 showed the result of ANOVA establishing the spatial variation in the psycho-social effects of abandonment between the two areas of Ilorin. According to the table, it is observed that some of the effects of abandoned structures do not vary significantly between areas with $\mathrm{F}=0.783$ and $\mathrm{P}=0.388$. The probability value suggests that there is no significant variation in the causes of abandonment between the two areas of Ilorin at $95 \%$ confidence level. It can therefore be inferred that the psycho-social effect of abandoned structures between urban and rural do remain the same in the study area.

\subsection{Economic Impact of Abandonment (EcIAI) Observed in the Study Area}

This section provides an insight into the urban-rural variation in the economic impact of abandonment observed by residents in their environment. Presented in Table 7 are the EcIAI value for the whole study area and each area. The mean EcIAI for the whole study area is 3.70, a value higher than the EcIAI value of urban area with 3.68 but less than that of rural area with 3.71. It could then be concluded that economic effects of abandonment incidence is felt by rural dwellers (probably because they let out buildings as a source of income) more than urban dwellers.

Considering the study area as a whole, some economic variables have higher effects than others. These include 'affecting communal development levy' (EcIAI $=3.88)$; and 'property value decline' $($ EcIAI $=3.61)$ and 'property vandalization' (EcIAI $=3.60)$. Category of economic variables for which residents observed less economic effect include 'property vandalization' $($ EcIAI $=3.60)$. It can therefore be concluded that the most and least economic effects perceived by residents in the study area include 'communal development levy decline' and 'property vandalization'. The implication of these is when there is need for community development project which is based on building population of the area; there is tendency that income expected may not be realized due to incidence of abandoned building. It then leads to decrease in communal development expected income or increase in communal development levy for the available dwellers.

In the urban area, residents perceived high level of economic effect of abandonment about certain variables. These are greater risk of 'affecting communal development levy' (EcIAI = 3.81); 'property value decline' $(\mathrm{EcIAI}=3.63)$. Category of economic variables for which residents observed less economic effect in urban area include 'property vandalization' (EcIAI $=3.60)$. It can therefore be inferred that the most and least psycho-social effects perceived by residents in urban area include 'affecting communal development levy' and 'property vandalization'.

In the rural area, residents considered certain variables have high economic effects. This is 'affecting communal development levy' (EcIAI $=3.95)$. Category of variables for which residents observed less economic effect in rural area include 'property vandalization and property value decline' (EcIAI $=3.59$ ) each. It can therefore be deduced that the most and least psycho-social effects perceived by residents in rural area are recorded in respect of 'affecting communal development levy' and 'property vandalization'.

Table 7: Economic Impact of Abandoned Structures (EcIAI) in the Study Area.

\begin{tabular}{|c|c|c|c|c|c|}
\hline \multirow[t]{2}{*}{ Variables } & $\begin{array}{l}\text { EcJAI } \\
\text { Areas }\end{array}$ & for & EcIAI & \multirow[t]{2}{*}{$\begin{array}{l}\text { ECIAT } \\
* \text { EcIAI }\end{array}$} & \multirow[t]{2}{*}{$\begin{array}{l}-(\text { EcIAI } \\
\left.{ }^{*} \text { EcIAI }\right)^{2}\end{array}$} \\
\hline & Urban & Rural & & & \\
\hline $\begin{array}{l}\text { Affect Communal Development } \\
\text { levy }\end{array}$ & 3.81 & 3.95 & 3.88 & 0.18 & 0.0324 \\
\hline Property Value Decline & 3.63 & 3.59 & 3.61 & -0.09 & 0.0081 \\
\hline Property Vandalization & 3.60 & 3.59 & 3.60 & -0.10 & 0.0100 \\
\hline Total & 11.04 & 11.13 & 11.09 & & \\
\hline *EcIAI & 3.68 & 3.71 & 3.70 & & \\
\hline
\end{tabular}

Source: Author's Field Survey, 2015 
Table 8: Urban -Rural Variation in Economic Impacts of Abandoned Structures in the Study area.

\begin{tabular}{|l|r|r|r|r|r|}
\hline & \multicolumn{1}{|c|}{ Sum of Squares } & df & Mean Square & F & Sig. \\
\hline Between Groups & .001 & 1 & .001 & .048 & .837 \\
Within Groups & .112 & 4 & .028 & & \\
Total & .114 & 5 & & & \\
\hline
\end{tabular}

Source: Author's Field Survey, 2015

Table 8 showed the result of ANOVA establishing the spatial variation in the economic effects of abandonment between the two areas of Ilorin. According to the table, it is observed that some of the effects of abandoned structures do not vary significantly between areas with $\mathrm{F}=0.048$ and $\mathrm{P}=0.837$. The probability value suggests that there is no significant variation in the economic effect of abandonment between the two areas of Ilorin at $95 \%$ confidence level. It can therefore be inferred that the economic effect of abandoned structures between urban and rural do remain the same in the study area.

\subsection{Suggested Solutions to Eradicate the Problem of Structure Abandonment in the Study Area}

This section is concerned with the level of agreement of respondents on the suggested solutions to eradicate/reduce the incidence of abandonment of structures in the study area and the society at large. Presented on Table 9 are the Suggested Solutions to Abandonment Index (SSA) made by residents of the two areas of Ilorin.

Rural area has the highest mean SSA value of 4.11 compared to the urban area with SSA value of 4.04. The mean SSA value for the study area is 4.10. The mean SSA value of rural area is above the mean SSA for the study area while mean SSA value for urban area is below it. This implies that majority of the rural dwellers strongly agreed with the suggested solution than the residents of the urban area.

On the aggregate level, the level of agreement on the possible suggested solutions made by respondents in the study area include 'increase in basic salary' (SSA = 4.45); 'proper selection of site before commencement of building projects' (SSA $=4.32$ ); 'maintenance culture among citizen should be enforced' (SSA $=4.31$ ); 'local planning authority should be charged with blight control' (SSA = 4.25); and improvement in nations economy (SSA $=4.17)$. The level of disagreement on the possible suggested solutions made by respondents in the study area include 'government should acquire all abandoned structures' (SSA = 3.79), 'abandoned structures should be sold out by the owner' (SSA = 3.28). From the above analysis it can be deduced that some of the sampled respondents may own an abandoned building(s) in one location or the other that is why they strongly disagreed that government should acquire all abandoned buildings. It can therefore be inferred that majority of the residents in the study area strongly agreed that there should be increase in the basic salary as well as proper consideration of site before commencement of building project, enforcement of maintenance culture among citizens and general improvement in nations economy. Most of the residents reported that if all this suggestions are put in place, then structure abandonment will reduce to barest minimum.

In the urban area of Ilorin, the level of agreement of respondents to the possible suggestions include 'increase in basic salary' (SSA = 4.31), 'local planning authority should be charged with blight control' (SSA = 4.29), 'proper selection of site before commencement of building projects' (SSA = 4.28), 'maintenance culture among citizens should be enforced' $(\mathrm{SSA}=4.21)$ and 'improvement in nation's economy' (SSA $=4.07)$ while suggested solutions with high level of disagreement among the urban dwellers include abandoned structures should be sold out (SSA $=3.37)$ and 'acquisition of abandoned structures by the government' $(\mathrm{SSA}=3.77)$.It is observed in the urban area that some of the sampled respondents may own an abandoned building either within their residing area or outside, but they do not want to part with it, that is why they disagreed that abandoned structures should be sold out. In light of this, they believed that their children can be more financially okay and put their abandoned buildings into completion stage. It can therefore be deduced that most of the urban dweller strongly agreed that there should be increase in the basic salary, also charging the local planning authority to control blight as well as proper consideration of site before commencement of building project, also enforcement of maintenance culture among citizens and general improvement in nation's economy.

Furthermore, in the rural area of Ilorin, the level of agreement of respondents to the possible suggestions include 'increase in basic salary' (SSA $=4.58)$, 'maintenance culture among citizen should be enforced' (SSA = 4.41 ), 'proper consideration of site before commencement of building projects' (SSA $=4.35$ ), 'improvement in nation's economy' (SSA $=4.27)$ and charging the local planning authority to control blight $(\mathrm{SSA}=4.27)$ while suggestions with high level of disagreement among the rural dwellers include abandoned structures should be sold out $(\mathrm{SSA}=3.18)$ and 'government should acquire all abandoned structures' $(\mathrm{SSA}=3.80)$.It can be deduced that rural dwellers strongly to virtually all the suggested solutions to abandoned structures as a possible way forward to reduce the incidence of structure abandonment to barest minimum. It can therefore be concluded that most of the rural dweller strongly agreed that there should be increase in the basic salary, enforcement of maintenance culture among citizens as well as proper consideration of site before commencement of building project, general improvement in nation's economy and also charging the local planning authority to control 
blight.

Table 9: Urban-Rural Variation of Possible Suggestions Made by Respondents in the study area.

\begin{tabular}{|c|c|c|c|c|c|}
\hline \multirow[t]{2}{*}{ Suggestions } & \multicolumn{2}{|c|}{ SSA for Areas } & \multirow[t]{2}{*}{ SSA } & \multirow{2}{*}{$\begin{array}{l}\text { SSA- * } \\
\text { SSA }\end{array}$} & \multirow{2}{*}{$\begin{array}{l}\text { (SSA }-* \\
\text { SSA) }\end{array}$} \\
\hline & Urban & Rural & & & \\
\hline Increase basic salary & 4.31 & 4.58 & 4.45 & 0.38 & 0.1444 \\
\hline $\begin{array}{l}\text { Proper site selection should be considered } \\
\text { before commencement of building projects }\end{array}$ & 4.28 & 4.35 & 4.32 & 0.25 & 0.0625 \\
\hline $\begin{array}{l}\text { Maintenance culture should be enforced among } \\
\text { citizens }\end{array}$ & 4.21 & 4.41 & 4.31 & 0.23 & 0.0529 \\
\hline $\begin{array}{l}\text { Local planning authority should be charged to } \\
\text { blight control }\end{array}$ & 4.29 & 4.21 & 4.25 & 0.18 & 0.0324 \\
\hline Improvement in nations economy & 4.07 & 4.27 & 4.17 & 0.10 & 0.0100 \\
\hline $\begin{array}{l}\text { Government should acquire all abandoned } \\
\text { structures }\end{array}$ & 3.77 & 3.80 & 3.79 & -0.23 & 0.0529 \\
\hline Abandoned structures should be sold out & 3.37 & 3.18 & 3.28 & -0.79 & 0.6241 \\
\hline Total & 28.30 & 28.80 & 28.55 & & \\
\hline * SSA & 4.04 & 4.11 & 4.07 & & \\
\hline
\end{tabular}

Source: Author's Computation (2015)

Table 10: Chi Square Summary of suggested solutions to incidence of abandonment.

\begin{tabular}{|c|c|c|c|c|c|c|}
\hline $\mathbf{S} / \mathbf{N}$ & Variables & $\begin{array}{l}\text { Nature of } \\
\text { Variation }\end{array}$ & $\begin{array}{l}\mathrm{X} 2 \\
\text { value }\end{array}$ & D & $\begin{array}{l}P \\
\text { value }\end{array}$ & Remark \\
\hline 1 & Improve Nations Economy & Urban-rural & 6.401 & 1 & 0.002 & Significant \\
\hline 2 & Increase Basic Salary & Urban-rural & 1.739 & 3 & 0.003 & Significant \\
\hline 3 & Abandoned Structure Should be Sold Out & Urban-rural & 2.736 & 2 & 0.409 & Insignificant \\
\hline 4 & $\begin{array}{l}\text { Enforce Maintenance Culture Among } \\
\text { Citizens }\end{array}$ & Urban-rural & 1.837 & 3 & 0.068 & Insignificant \\
\hline 5 & $\begin{array}{l}\text { Government Should Acquire all } \\
\text { Abandoned Structures }\end{array}$ & Urban-1 & 1.275 & 2 & 0.889 & Insignificant \\
\hline 6 & $\begin{array}{l}\text { Local Planning Authority Should be } \\
\text { Charge with Blight Control }\end{array}$ & Urban-rural & 2.440 & 4 & 0.334 & Insignificant \\
\hline 7 & $\begin{array}{l}\text { Proper Site Selection Should be } \\
\text { Considered Before Commencement of } \\
\text { building projects }\end{array}$ & Urban-rural & 1.836 & 4 & 0.087 & Insignificant \\
\hline
\end{tabular}

Source: Author's Field Survey, 2015

\subsection{Conclusion and Recommendation}

This study is one of the few research efforts in the field of Urban and Regional Planning in Nigeria that investigated the impact of abandoned structures within the context of rural and urban areas of Ilorin. Previous research efforts concentrated on abandoned structures in urban centres only, neglecting abandonment in the rural areas. Thus, the study examined the impacts (environmental, psycho - social and economic) of abandoned structures in both urban and rural areas of Ilorin, Nigeria. The study provide a cross comparative approach between urban and rural areas of Ilorin. Previous studies concluded on the environmental effects of abandoned structures predominantly in urban centers but this study was able to investigate the incidence, causes and impacts of abandonment on rural dwellers as well.

The study also provided empirical evidences on prevalence of abandoned structures, its impact (environmental, psycho-social and economic) of abandonment in urban and rural areas in the third world cities. It also provide a window to see the situation of abandonment in the urban and rural setting in the third world countries since abandoned structures cut across the urban and rural landscape as well as rural areas. Furthermore, this research work provides basic information that will guide the policy makers on the control of incidence of abandoned structures in Ilorin. It allows a suitable policy formulation for its housing management and livability dweller in a particular area. It will also contribute to the existing literatures and housing stock management in Nigeria. 
Summarily the study has been able to establish that there is significant relationship between incidence of abandoned structures and residents' livability. It also established that there is significant variation in the incidence and causes of abandoned structures between urban and rural areas of Ilorin. The study therefore suggests that abandoned structure should be identified and compiled by Town Planning Authorities after which the owners could be contacted and mandated to work on the structures based on the level of negative impacts associated with such structures. Efforts could also be made to stipulate period of time for which structure could be completed otherwise the government will take other necessary actions. Some of the government owned abandoned properties could be auctioned or donated to the respective community for better usage.

\section{REFERENCES}

Matthew Carmona (2019): Place Quality and its impact on Health, Social, Economic and Environmental Outcomes. Journal of Urban Design. Volume 24 (1)

J.E Ahianba, K.O Dimuna and G.R.A Okogun (2008): Built Environment Decay and Urban Health in Nigeria. Journal of Human Ecology. Volume 23(3).

Adedibu, A. A. and Akindele, O. A. (2007). The Significance of Landed Property Abandonment in Osogbo: A Planner's perspective. Journal of Nigerian Institute ofTown Planners Vol XX No 1

Akindele, O.A. (2013). Environmental Effects of Abandoned Landed Properties in Ogbomoso and Osogbo, Nigeria. Ethiopia Journal of Environmental Studies and Management. Vol 6

Folke, C (2007). The Problem of Fit between Ecosystems and Institutions: Ten Years Later. Journal of Ecology and Society vol $12 \mathrm{pp} 30$.

Olatubara, C.O. (2007). Fundamentals of Housing, In Tunde Agbola, Layi Egunjobi and C.O Olatubara (eds) Housing development and management: A book of readings, department of urban and regional planning, university of Ibadan, Nigeria. Pg 70-106

Osuide, S.O. and Dimuna, K.O (2005). None Compliance with Building Bye-laws and Regulations in Nigeria the dangers ahead. The Built Environment Journal of International Institute for Building Research (IIBR), 1(1): .62-68

Sampford, C. (2010). Environmental Governance viewed 28 May 2015, www.iucn.org/about/work/programmes/environmental_law/elp_work/elp_work_issues/e p_work_governance

Setterfield, M. (1997). Abandoned Buildings: Models for Legislative and Enforcement Reform. http:/www.trincoll.edu/depts./tcn/research report/resrch23.htm.

UN-Habitat (2009). Meeting Development Goals in Small Urban Centers: Water and Sanitation in the World's Cities. Earthscan publication, London. (Accessed on: 27 August).

United State Environmental Management Department (2009). Terms of environment. http://wwwemd.gov/OCEMDterms/terms.Html. 